\title{
Gut Microbiota and Metabolic Endotoxemia in Young Obese Mexican Subjects
}

\author{
Romina Belén Radilla-Vázquez ${ }^{a} \quad$ Isela Parra-Rojas $^{a}$ \\ Norma Edith Martínez-Hernández ${ }^{\mathrm{b}} \quad$ Yolanda Fabiola Márquez-Sandovalc \\ Berenice Illades-Aguiar ${ }^{a}$ Natividad Castro-Alarcón ${ }^{a}$ \\ a Unidad Académica de Ciencias Químico-Biológicas, Universidad Autónoma de Guerrero, \\ Chilpancingo, México; ${ }^{b}$ Laboratorio Estatal de Salud Pública Galo Soberón y Parra, \\ Secretaria de Salud Guerrero, Acapulco, México; ' Cuerpo Académico 454, Laboratorio de \\ Evaluación del Estado Nutricional, Departamento de Reproducción Humana, Crecimiento y \\ Desarrollo Infantil, Centro Universitario de Ciencias de la Salud, Universidad de Guadalajara, \\ Jalisco, México
}

\section{Key Words}

Gut microbiota · Metabolic endotoxemia · Obesity

\begin{abstract}
Background: The gut microbiota plays an important role in human metabolism; previous studies suggest that the imbalance can cause a metabolic endotoxemia that may be linked to weight gain and insulin resistance. The purpose of this study was to investigate the relationship between the gut microbiota composition, the lipopolysaccharide levels and the metabolic profile in obese and normal-weight young subjects. Methods: We studied 32 obese $\left(B M I \geq 30 \mathrm{~kg} / \mathrm{m}^{2}\right)$ and 32 normal-weight subjects $\left(B M I=18.5-24.9 \mathrm{~kg} / \mathrm{m}^{2}\right)$, aged $18-25$ years. Quantification of intestinal bacteria was performed by real-time PCR. Endotoxin units were determined with the test QCL-1000, and biochemical profile was performed under a standard protocol of Spinreact. Results: Obese individuals had a BMI of $34.5(32.9-36.45) \mathrm{kg} / \mathrm{m}^{2}$, increased triglycerides (123 vs. $70 \mathrm{mg} / \mathrm{dl}$ ), total cholesterol (168 vs. $142 \mathrm{mg} / \mathrm{dl})$, and LDL-cholesterol (114 vs. $96.5 \mathrm{mg} / \mathrm{dl}$ ). In obese subjects body temperature was higher than in normalweight subjects. We found a greater number of Clostridum leptum and Lactobacillus ( $p<$ $0.001)$ and lower numbers of Prevotella and Escherichia coli $(p<0.001)$ in the obese group. A decrease of $E$. coli was associated with an increased risk of lipopolysaccharide levels ranging from 1 to $1.3 \mathrm{EU} / \mathrm{ml}$. A positive correlation was found between serum lipopolysaccharides and BMI $(r=0.46, p=0.008)$, triglyceride levels $(r=0.44, p=0.011)$ as well as waist circumference
\end{abstract}


Radilla-Vázquez et al.: Gut Microbiota and Metabolic Endotoxemia in Young Obese Mexican Subjects

$(r=0.34, p=0.040)$, being more evident in young obese females. Conclusion: Subclinical metabolic endotoxemia determined by serum concentration of lipopolysaccharides was related to the smallest amount of $E$. coli, high triglyceride levels, and central adiposity in obese young persons.

(C) 2016 S. Karger GmbH, Freiburg

\section{Introduction}

Obesity is now considered a major public health concern globally as it predisposes to a number of chronic human diseases [1]. The major cause of obesity is a positive energetic balance resulting from an increased energy intake from the diet and a decreased energy output associated with low physical activity $[2,3]$. However, obesity is a complex chronic disorder with a multifactorial etiology, involving genetics, hormones, diet, and environment [4]. In addition, recent studies have focused on intestinal microbiota as environmental factors that increase energy yield from diet, regulate peripheral metabolism, and thereby increase body weight [5].

The gut microbiota contains approximately $10^{12}$ cells/g of feces. However, the composition of gut microbiota can vary among humans, according to age, food habits and environmental factors, and the vast majority of microorganisms belong to the phyla of Firmicutes (Gram-positive), Bacteroidetes (Gram-negative), Actinobacteria (Gram-positive), and Proteobacteria (Gram-negative) [4,6]. The Firmicutes is the largest bacterial phylum and contains more than 200 genera, including Lactobacillus, Mycoplasma, Bacillus, and Clostridium. The Bacteroidetes includes the genus Bacteroides (limited to species within the Bacteroides fragilis group). The Actinobacteria including the genus Bifidobacterium (considered as probiotic) and the Proteobacteria belong to a variety of pathogenic bacteria (e.g. Escherichia coli) [5, 7].

Several studies reported that obesity is associated with a low abundance of intestinal Bacteroidetes and a high abundance of Firmicutes [8-10]. However, these findings are in disagreement with two other more recent human studies [11,12], which showed that no difference was found in the proportions of Bacteroidetes and Firmicutes in the feces of lean and obese subjects.

Even though the exact role of gut bacteria in obesity development is still obscure, it has been proposed that changes in gut microbiota composition in response to high-fat diets affect lipogenesis, gut permeability for lipopolysaccharides (LPS), and the inflammatory status as well as the endocannabinoid system tone [13].

The LPS found in the outer membrane of Gram-negative bacteria act as endotoxins and can elicit strong immune responses. LPS are large glycolipids that consist of lipid and polysaccharide fractions joined by a covalent bond. The lipid A is a phosphorylated glucosamine disaccharide acylated with hydroxyl-saturated fatty acids one of which anchors in the bacterial membrane. It is responsible for much of the toxicity of Gram-negative bacteria. The core oligosaccharide attaches directly to lipid A. The 0 antigen, a repetitive glycan polymer, is attached to the core oligosaccharide and comprises the outermost domain of the LPS molecule [14]. LPS in Bacteroides fragilis has an unusual structure and is 10 to 1,000 times less toxic than that of E. coli [7]. It is claimed that gut microbiota composition can affect the host homeostasis modulating subclinical systemic inflammation [2,14].

An increased level of LPS in obese individuals is mostly due to processes involving the transport of LPS from the gut to the blood, e.g., increase in chylomicron-driven transport of LPS, a rupture of the gut barrier integrity leading to abnormal gut permeability, and a decrease in processes involved in intestinal LPS degradation (alkaline phosphatase activity). Once LPS reach blood circulation, they cause metabolic endotoxemia, which thereby activates the 
macrophages in the different tissues leading to a low-level inflammation being part of the metabolic alterations occurring upon obesity $[2,15]$. In the adipose tissue, LPS trigger inflammation by inducing release of pro-inflammatory and chemotactic molecules from local macrophages and preadipocytes [14].

The objective of this study was to investigate the relationship between major bacterial groups of gut microbiota, the LPS levels and the metabolic profile in young obese and normalweight subjects. In this study, real-time PCR was used to quantify the main groups of gut microbiota, establishing the basis for subsequent studies, focusing on the gut microbiota composition which might be a novel target for treating chronic diseases.

\section{Material and Methods}

\section{Participants}

The subjects were selected during the period of June to November 2012 in Chilpancingo, a city localized in Southern Mexico. Participants were both of sexes and aged between 18 and 25 years. Body weight was measured in light clothes without shoes using a Tanita BC-553. Body circumference was measured using a diameter tape and height was measured using a stadiometer. The Research Ethics committee of Guerrero University approved the study; all participants agreed to participate in the study by means of informed consent in writing and completed the questionnaire about history/lifestyle. They were classified into two study groups, with 32 obese $\left(\mathrm{BMI} \geq 30 \mathrm{~kg} / \mathrm{m}^{2}\right)$ and 32 normal-weight $\left(\mathrm{BMI}=18.5-24.9 \mathrm{~kg} / \mathrm{m}^{2}\right)$ subjects. No antibiotics had been taken in the 4 weeks prior to study by any of the youth. Subjects with probiotic and prebiotic supplementation, hypocaloric diets, and chronic and infectious disease as well as pregnant women were excluded.

\section{Laboratory Measurements}

A fasting blood sample was obtained from each youth for the measurement of the following parameters. Glucose, cholesterol, triglyceride, HDL-cholesterol and LDL-cholesterol levels were obtained using a standard protocol of Spinreact (Girona, Spain). Endotoxin units were determined using Limulus Amebocyte Lysate kit (QCL-1000, Lonza, MD, USA); FDA-approved, endotoxin standard solution was prepared at concentrations ranging from 0.1 to $1.0 \mathrm{UE} / \mathrm{ml}$ to construct a standard curve. The absorbance from each microplate well was measured at $405 \mathrm{~nm}$ (TECAN 3500, Grödig, Austria).

\section{Gut Microbiota Analysis}

The DNA extractions from pure cultures of the control strain and fecal samples were extracted by using the QIAamp DNA stool Mini kit (Qiagen, Hilden, Germany). To characterize gut microbiota, PCR primers were used to target different species or groups of gut microbiota (table 1). Quantitative PCR (qPCR) was conducted as previously described [12,16-18]. Briefly, the amplification and detection were performed with a 7500 Fast Real-Time PCR System (Applied Biosystems, Foster City, CA, USA). Each reaction mixture of $25 \mu$ l was composed of SYBR Green qPCR Master Mix (Applied Biosystems), $1 \mu \mathrm{l}$ of each of the specific primers at a concentration of $0.25 \mu \mathrm{mol} / \mathrm{l}$, and $1 \mu \mathrm{l}$ of template DNA (10-30 ng). The fluorescent products were detected at the last step of each cycle. A melting curve analysis was made after amplification to distinguish the targeted PCR product from the non-targeted PCR product. A curve standard was done using the E. coli. reference strain ATCC 25922. ATCC 25922 was added in serial dilutions from $5 \times 10^{6}$ to $5 \times 10^{2}$ cells to a series of PCR mixtures with $E$. coli-specific primers.

\section{Statistical Analysis}

The descriptive analysis was performed using frequencies and chi square test for categorical variables. Parametric variables were reported as mean and standard deviation, the significance of differences between groups was determined using Student's t test. Non-parametric data were expressed as medians and percentiles (25th and 75th), statistical differences were determined using the Mann-Whitney U test. Spearman's correlation coefficients were computed to assess the associations between some variables in all youths. Kruskal-Wallis test were used to find differences between Gram-negative bacteria and LPS. Statistical analysis was done using STATA software (V.11; College Station, TX, USA), and p $<0.05$ was reported as statistically significant. 
Radilla-Vázquez et al.: Gut Microbiota and Metabolic Endotoxemia in Young Obese Mexican Subjects

Table 1. Sequence of primers for real-time PCR

\begin{tabular}{|c|c|c|c|c|}
\hline Target & Sequence & Size (bp) & $\operatorname{Tm}\left({ }^{\circ} \mathrm{C}\right)$ & Reference \\
\hline Total bacteria & $\begin{array}{l}\text { ACTCCTACGGGAGGCAGCAGT } \\
\text { ATTACCGCGGCTGCTGGC }\end{array}$ & 600 & 60 & 12 \\
\hline \multicolumn{5}{|l|}{ Firmicutes } \\
\hline Clostridium leptum & $\begin{array}{l}\text { GCACAAGCAGTGGAGT } \\
\text { CTTCCTCCGTTTTGTCAA }\end{array}$ & 239 & 50 & 16 \\
\hline Lactobacillus & $\begin{array}{l}\text { TACATCCCAACTCCAGAACG } \\
\text { AAGCAACAGTACCACGACC }\end{array}$ & 90 & 55 & 17 \\
\hline \multicolumn{5}{|l|}{ Bacteroidetes } \\
\hline Bacteroides fragilis & $\begin{array}{l}\text { ATAGCCTTTCGAAAGRAAGAT } \\
\text { CCAGTATCAACTGCAATTTTA }\end{array}$ & 495 & 50 & 16 \\
\hline Prevotella & $\begin{array}{l}\text { CACRGTAAACGATGGATGCC } \\
\text { GGTCGGGTTGCAGACC }\end{array}$ & 513 & 55 & 16 \\
\hline $\begin{array}{l}\text { Actinobacteria } \\
\text { Bifidobacterium }\end{array}$ & $\begin{array}{l}\text { CTCCTGGAAACGGGTGG } \\
\text { GGTGTTCTTCCCGATATCTACA }\end{array}$ & 550 & 55 & 16 \\
\hline $\begin{array}{l}\text { Protobacteria } \\
\text { Escherichia coli }\end{array}$ & $\begin{array}{l}\text { CATGCCGCGTGTATGAAGAA } \\
\text { CGGGTAACGTCAATGAGCAAA }\end{array}$ & 95 & 55 & 18 \\
\hline
\end{tabular}

\section{Results}

\section{Subject Characteristics}

The mean age of the youths studied was 21 years, with homogeneous distribution by sex. In the obese group, 29 were healthy and 3 had metabolic syndrome. Obese youths had a BMI of $34.5(32.9-36.45) \mathrm{kg} / \mathrm{m}^{2}$, triglycerides, cholesterol, LDL-cholesterol, body temperature, and waist circumference were significantly larger in obese youths when compared with normal-weight group. Glucose and HDL-cholesterol values were normal in both groups. Serum LPS levels in obese and normal-weight youths were 1.22 (0.96-1.51) endotoxin units $(\mathrm{EU}) / \mathrm{ml}$ and $1.14(0.72-1.31) \mathrm{EU} / \mathrm{ml}$, respectively (table 2). Correlation of clinical and biochemical variables demonstrated that only body temperature and BMI were positively correlated $(r=0.387, p=0.001)$.

\section{Quantification of Gut Microbiota}

The total bacteria numbers in fecal samples were higher in normal-weight youths $(11.0$ $\log _{10}$ cell/g) than in obese youths $\left(10.7 \log _{10} \mathrm{cell} / \mathrm{g} ; \mathrm{p}=0.046\right)$. However, obese youths have larger numbers of Clostridum leptum and Lactobacillus ( $\mathrm{p}<0.001)$, and lower numbers of Prevotella and E. coli $(\mathrm{p}<0.001)$. The amounts of B. fragilis and Bifidobacterium did not differ between both study groups (table 3 ).

Gram-positive bacterial species the counts of which differed statistically or tended to differ between lean and obese individuals were included in the correlation analyses with clinical and biochemical variables. Only, C. leptum showed positive correlation with BMI ( $\mathrm{r}=$ $0.414, p=0.007)$ and triglycerides $(r=0.306, p=0.013)$, which may be involved in weight gain.

Correlation between LPS, Clinical Variables and Gram-Negative Bacteria

The LPS levels tended to positively correlate with BMI being higher in obese youths $(\mathrm{r}=$ $0.46, p=0.008)$ than in the normal-weight group $(r=0.30, p=0.092)$. Regarding triglycerides, 
Radilla-Vázquez et al.: Gut Microbiota and Metabolic Endotoxemia in Young Obese Mexican Subjects

Table 2. Clinical and biochemical characteristics of the study subjects

\begin{tabular}{|c|c|c|c|}
\hline & $\begin{array}{l}\text { Normal weight } \\
(\mathrm{n}=32)\end{array}$ & $\begin{array}{l}\text { Obese } \\
(n=32)\end{array}$ & $\mathrm{p}$ value \\
\hline Age $^{\mathrm{a}}$, years & $21.06 \pm 1.93$ & $21.43 \pm 1.93$ & 0.443 \\
\hline \multicolumn{4}{|l|}{$\operatorname{Sex}^{\mathrm{b}}, \%$} \\
\hline Female & $19(59.38)$ & $16(50.0)$ & \multirow[b]{2}{*}{0.451} \\
\hline Male & $13(40.63)$ & $16(50.0)$ & \\
\hline $\mathrm{BMI}^{\mathrm{c}}, \mathrm{kg} / \mathrm{m}^{2}$ & $21.35(19.85-22.8)$ & $34.5(32.9-36.45)$ & $<0.001^{*}$ \\
\hline Waist circumference ${ }^{\mathrm{c}}, \mathrm{cm}$ & $78.75(73.6-81)$ & $108.5(102.6-116.1)$ & $<0.001^{*}$ \\
\hline Temperature ${ }^{\mathrm{c}},{ }^{\circ} \mathrm{C}$ & $35.85(35.5-36.45)$ & $36.3(36.15-36.75)$ & $0.001^{*}$ \\
\hline Glucose $^{c}, \mathrm{mg} / \mathrm{dl}$ & $81(75-84.5)$ & $80(74.5-87.5)$ & 0.999 \\
\hline Cholesterol $^{\mathrm{c}}, \mathrm{mg} / \mathrm{dl}$ & $142(109.5-165)$ & $168(151-194.5)$ & $<0.001^{*}$ \\
\hline HDL-cholesterol' $^{\mathrm{C}}, \mathrm{mg} / \mathrm{dl}$ & $44.5(38-55.5)$ & $44(37-55)$ & 0.772 \\
\hline LDL-cholesterol' ${ }^{\mathrm{C}}, \mathrm{mg} / \mathrm{dl}$ & $96.5(80.5-119.5)$ & $114(107-149.5)$ & $0.002^{*}$ \\
\hline Triglycerides $^{\mathrm{c}}, \mathrm{mg} / \mathrm{dl}$ & $70(58.5-89.5)$ & $123(95.5-156.5)$ & $<0.001^{*}$ \\
\hline $\mathrm{LPS}^{\mathrm{c}}, \mathrm{EU} / \mathrm{ml}$ & $1.14(0.72-1.31)$ & $1.22(0.96-1.51)$ & 0.210 \\
\hline
\end{tabular}

${ }^{\mathrm{a}}$ Mean $\pm \mathrm{SD}$, Student's t test.

$\mathrm{b}_{\mathrm{n}}(\%)$ chi square test.

${ }^{c}$ Median (25th and 75th percentile) Mann-Whitney U test, statistical difference $(\mathrm{p}<0.050)$.

Table 3. Gut microbiota in obese and normal-weight young subjects ${ }^{\mathrm{a}}$

\begin{tabular}{llll}
\hline & $\begin{array}{l}\text { Normal weight } \\
\left(\log _{10} \text { cell/g of fecal) }\right.\end{array}$ & $\begin{array}{l}\text { Obese } \\
\left(\log _{10} \text { cell/g of fecal) }\right.\end{array}$ & p value \\
\hline Total bacteria & $11.0(10.6-11.2)$ & $10.7(10.4-11.0)$ & $0.046^{*}$ \\
\hline $\begin{array}{l}\text { Gram-positive } \\
\quad \text { C. leptum }\end{array}$ & & \\
$\quad \begin{array}{l}\text { Lactobacillus } \\
\text { Bifidobacterium }\end{array}$ & $7.2(7.5-8.3)$ & $8.9(8.3-8.9)$ & $<0.001^{*}$ \\
\hline $\begin{array}{l}\text { Gram-negative } \\
\text { B. fragilis }\end{array}$ & $6.9(6.2-6.4)$ & $6.8(5.9-7.8)$ & $<0.001^{*}$ \\
$\begin{array}{l}\text { Prevotella } \\
\text { E. coli }\end{array}$ & $9.2(8.5-9.6)$ & & 0.527 \\
\hline
\end{tabular}

${ }^{a}$ Median (25th and 75th percentile) Mann-Whitney U test.

*Statistical difference $(\mathrm{p}<0.050)$.

also a positive correlation was observed (fig. 1). Body temperature, cholesterol, and LDLcholesterol showed negative correlations with LPS levels.

LPS levels were slightly higher in women $1.20 \mathrm{EU} / \mathrm{ml}(0.85-1.52)$ than in men 1.16 $\mathrm{EU} / \mathrm{ml}$ (0.97-1.35), although this difference was not statistically significant. However, LPS levels showed positive correlation with waist circumference in women $(r=0.34, p=0.04)$. Also, triglycerides showed positive correlation with LPS levels in women (fig. 2).

We also assessed the correlation between Gram-negative bacteria and LPS levels (tertiles). A positive correlation was only found for E. coli, with the second tertile $(1-1.3 \mathrm{EU} / \mathrm{ml})$ presenting fewer bacteria compared to the first and third tertiles (table 4). In contrast, 
Radilla-Vázquez et al.: Gut Microbiota and Metabolic Endotoxemia in Young Obese Mexican Subjects

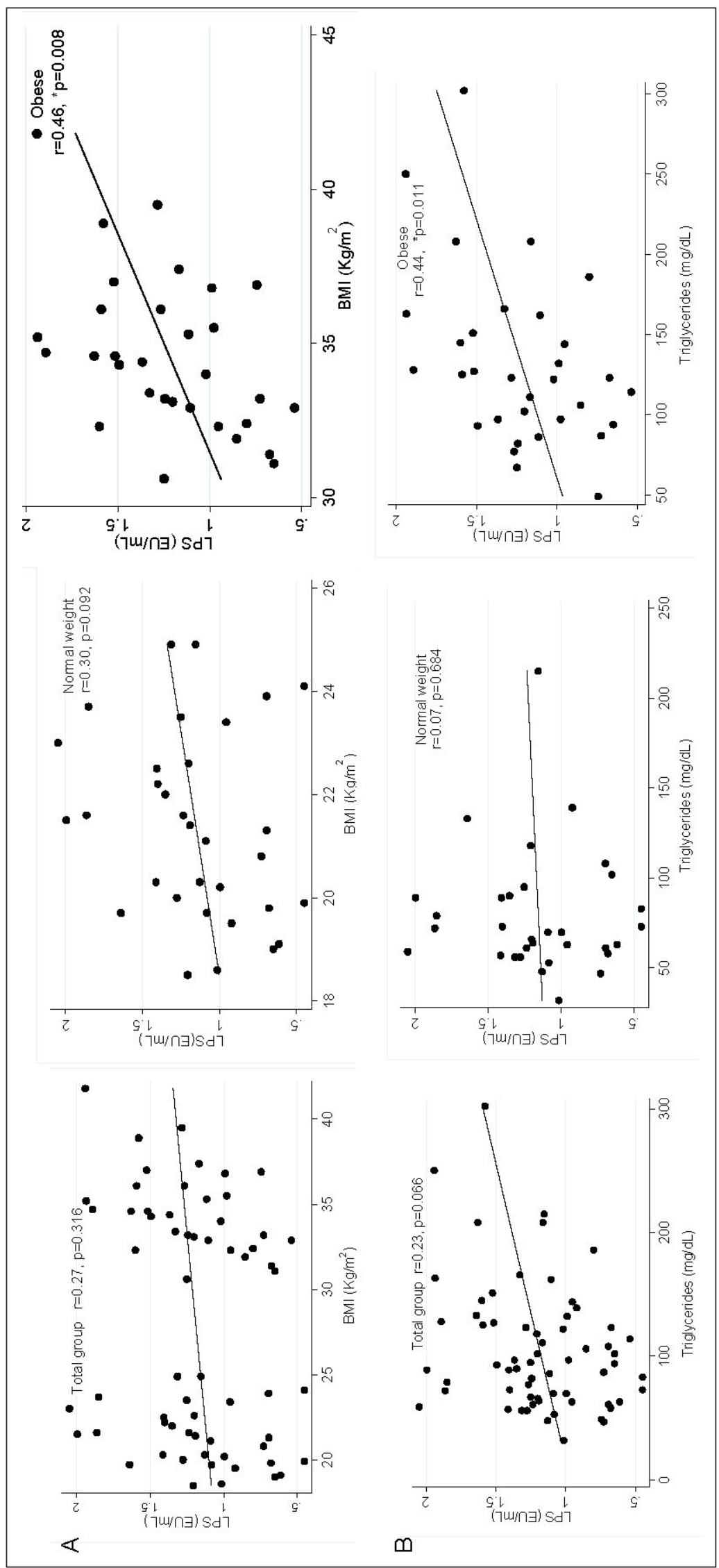

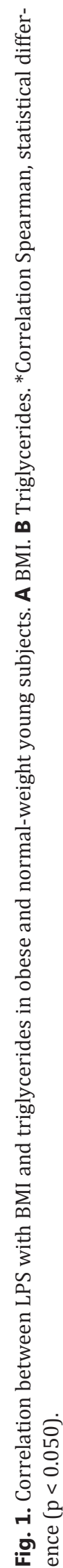


Radilla-Vázquez et al.: Gut Microbiota and Metabolic Endotoxemia in Young Obese Mexican Subjects

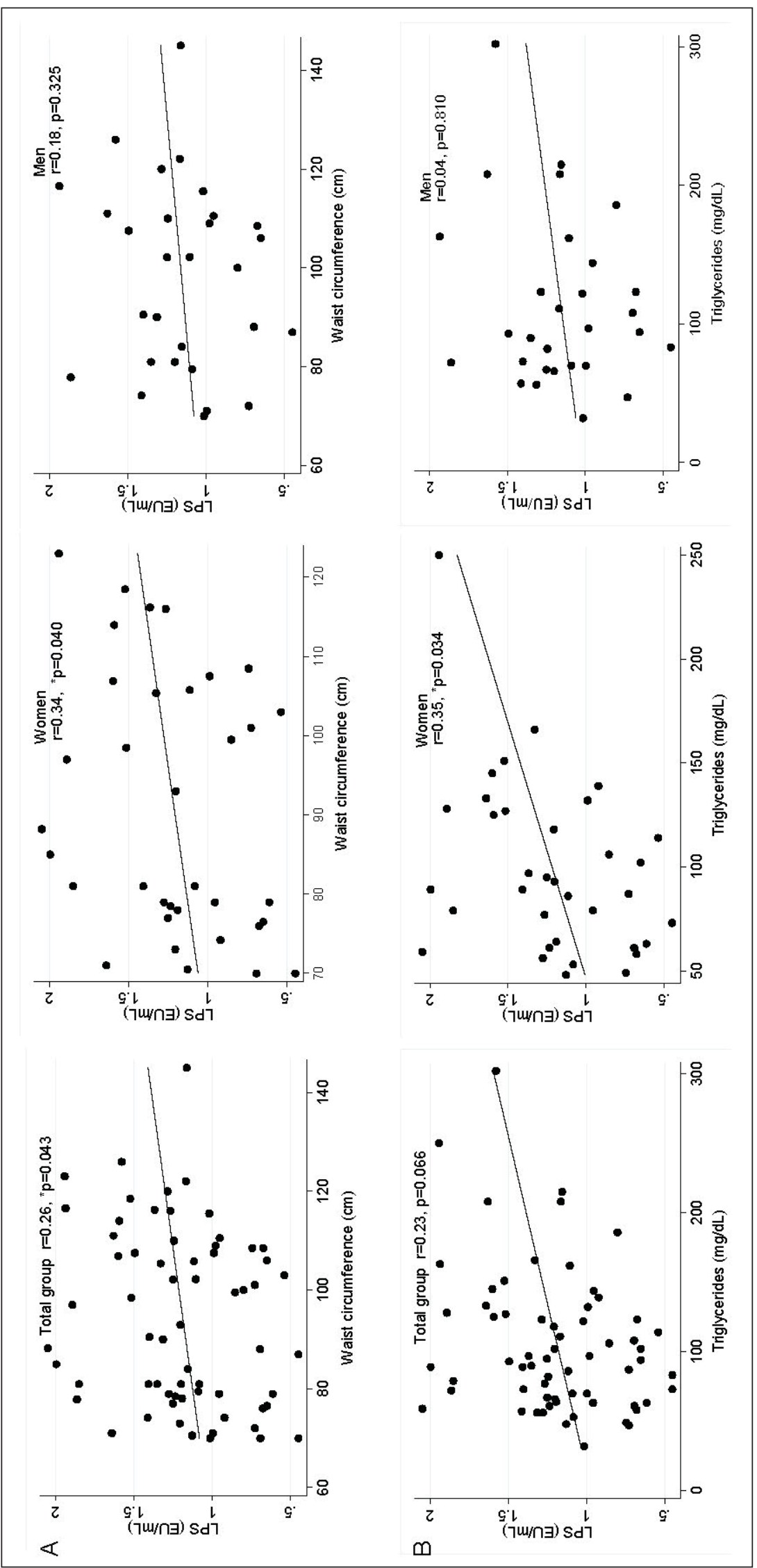

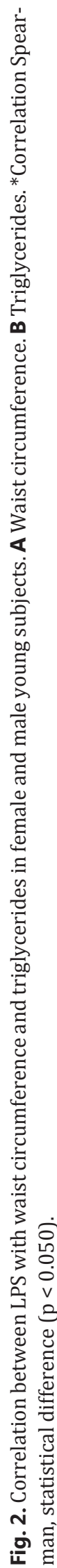


Radilla-Vázquez et al.: Gut Microbiota and Metabolic Endotoxemia in Young Obese Mexican Subjects

Table 4. Gram-negative bacteria and metabolic endotoxemia ${ }^{\mathrm{a}}$

\begin{tabular}{lllll}
\hline Gram-negative bacteria & $<1 \mathrm{EU} / \mathrm{ml}(\mathrm{n}=21)$ & $1-1.3 \mathrm{EU} / \mathrm{ml}(\mathrm{n}=21)$ & $>1.3 \mathrm{EU} / \mathrm{ml}(\mathrm{n}=22)$ & $\mathrm{p}$ value \\
\hline E. coli & $9.43(8.82-9.97)$ & $8.63(8.09-9.07)$ & $9.28(8.63-9.44)$ & $0.036^{*}$ \\
Prevotella & $7.05(6.4-7.39)$ & $7.12(6.4-7.39)$ & $7.37(6.4-7.39)$ & 0.789 \\
B. fragilis & $8.95(8.47-9.01)$ & $8.57(7.52-9.16)$ & $9.02(8.57-9.96)$ & 0.526 \\
\hline
\end{tabular}

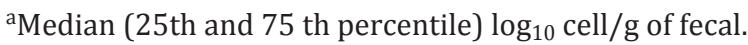

*Kruskal-Wallis test $(\mathrm{p}<0.050)$.

Prevotella and B. fragilis showed negative correlations. Since Gram-negative bacteria of gut microbiota are related to subclinical metabolic endotoxemia, we analyzed the relative risks of the different bacterial species. A low number of $E$. coli comes along with a greater risk of having high LPS levels $(\mathrm{OR}=4.378, \mathrm{p}=0.005)$ which could not be shown for Prevotella and B. fragilis.

\section{Discussion}

There is growing awareness of the importance of gut microbioma for health and disease and recognition that the microbe-to-host metabolic signaling is crucial to understand the mechanistic basis of their interaction [19]. In the present study, biochemical and anthropometric parameters for two study groups were determined. As expected, obese youths have high total cholesterol levels, LDL-cholesterol and triglycerides as well as a larger waist circumference and a higher body temperature. These variables indirectly reflect that the obese patients do not have a healthy lifestyle and that they are prone to suffer from metabolic disease in the long term.

In this study, we found an association between body temperature and BMI. This may be due to the fact that adipose tissue increases the synthesis and secretion of leptin that informs the brain of body fat levels. Via hypothalamus-adipose tissue crosstalk, neuropeptide Y stimulates food intake and white fat deposition and at the same time reduces brown fat activation and consequently thermogenesis [20].

The gut microbiota has been identified as a potential contributor to metabolic disease. It has been shown that obese individuals present different proportions of bacterial phyla compared with lean individuals, with an increase of Firmicutes and Actinobacteria and a decrease in Bacteroidetes [21]. We found a lower total bacteria count in obese youths compared with normal-weight subjects. Santacruz et al. [22] reported significant differences in total bacteria counts in fecal samples of low- and high-weight loss groups of adolescents before and after intervention based on an energy-restricted diet. In our opinion, this could be due to lower fiber but higher fat consumption and a greater prevalence of constipations in obese subjects [23]. The count of Gram-positive bacteria (C. leptum group and Lactobacillus) was higher in obese individuals, a result similar to those of Ley et al. [8] in 2006 and Armougom et al. [10] in 2009. These observations reinforce the possibility of a role of the Fimicutes in weight gain. In addition, significant statistical associations of the $C$. leptum group with high levels of triglycerides and BMI were found. In a gnotobiotic mouse model, the obesogenic properties of Clostridium ramosum were demonstrated by showing that this organism promotes body fat accumulation by enhancing intestinal glucose and lipid absorption [24]. 
Radilla-Vázquez et al.: Gut Microbiota and Metabolic Endotoxemia in Young Obese Mexican Subjects

The Gram-negative bacteria (E. coli and Prevotella) were lower in obese than in normalweight youths. In a recent study, the absence of $E$. coli was an independent predictor of weight gain $(O R=10.7$. Strikingly, patients with an $18 \%$ BMI increase showed a dramatic increase of Lactobacillus reuteri but no increase of E. coli [25]. These data may indicate the protective role of E. coli. Even though the B. fragilis cells numbers were constant in both study groups, the phylum Bacteroidetes has been associated with weight loss. Proposed mechanisms linking the microbiota to fat content and weight include differential effects of bacteria on the efficiency of energy extraction from the diet and changes in host metabolism of absorbed calories [26].

LPS is the most potent antigenic component of the Gram-negative bacterial cell wall and modulates the expression of various pro-inflammatory cytokines, activates production of lysosomal enzymes, and increases phagocytosis [27]. Thus, LPS may play a role in the lowgrade inflammation and insulin resistance, which can be observed in obesity. A high-fat diet also seems to increase the intestinal absorption of LPS, commonly known as metabolic endotoxemia $[6,13,21]$. In this study, we observed that the LPS level was higher in obese than in normal-weight subjects. Even if no significant difference was observed, these results are not congruent with previous studies. This may be due to smaller amount of Gram-negative bacteria (Prevotella and E. coli) in obese than in normal-weight subjects. LPS are constantly released within the gut by the lysis of Gram-negative bacteria, making them available for absorption into the bloodstream [15]. Thus it is conceivable that the differences observed may lead to significantly increased LPS blood levels in obese subjects in the future.

On the other hand, we observed that the increase of LPS levels positively correlate with triglyceride levels and BMI. These results suggest that fat was more efficient in transporting bacterial LPS from the gut lumen into the bloodstream, and adds to the knowledge of mechanisms responsible for relation between food intake and metabolic diseases as experimental data were found in apparently healthy men [28]. A study in Gambian women showed evidence for metabolic endotoxemia in obese and diabetic participants [29]. In our study increased LPS levels were accompanied by increased triglyceride levels and waist circumference in young obese females possibly reflecting an enhanced fat absorption and storage capacity in women compared to men.

This is in agreement with our findings that a low number of fecal $E$. coli is accompanied by higher LPS concentrations in the blood (1-1.3 EU/ml). On the other hand, this connection could not be verified for $B$. fragilis; however, this bacterium has a different LPS and is less toxic. Research about Prevotella bivia cell lysates isolated from the vagina resulted in higher LPS concentrations $(10,713.0 \pm 206.5 \mathrm{EU} / \mathrm{ml})$ than E. coli $(4,679.0 \pm 585.3 \mathrm{EU} / \mathrm{ml})$ or Gardnerella vaginalis ( $0.07 \pm 0.01 \mathrm{EU} / \mathrm{ml}$ of LPS) [30]. However, in this study Prevotella showed low risk in second tertile of endotoxemia (1-1.3 EU/ml). Further studies are required to determine the role of Gram-negative bacteria in producing LPS that modulate the expression of various pro-inflammatory cytokines in obesity. Thus it is known that other Gram-negative bacteria which were not investigated in the present study, particularly Proteobacteria as well as Enterobacter genera, induced obesity in mice, showed increased serum endotoxin load, and aggravated inflammatory conditions [31].

The limitations of this study include the relatively small sample size of groups. Moreover, we made no dietary survey to evaluate macronutrient consumption in order to establish the association of gut microbiota with the diet and absorbed calories. However, this study confirmed and complemented the results of the role of gut microbiota in the obese by using molecular techniques that target specific bacterial groups.

In conclusion, subclinical metabolic endotoxemia determined by serum concentrations of LPS was related to a smaller amount of $E$. coli, high triglyceride levels, and central adiposity in obese youths. 
Radilla-Vázquez et al.: Gut Microbiota and Metabolic Endotoxemia in Young Obese Mexican Subjects

\section{Acknowledgments}

This work was supported by Convocatoria de Apoyo al Fortalecimiento y Desarrollo de la Infraestructura Científica y Tecnológica 2014, clave 229958.

We thank Eugenia Flores Alfaro and Iris Paola Guzmán Guzmán for statistical analysis.

\section{Disclosure Statement}

The authors have disclosed no conflicts of interest.

\section{References}

1 Conterno L, Fava F, Viola R, Tuohy KM: Obesity and the gut microbiota: does up-regulating colonic fermentation protect against obesity and metabolic disease. Genes Nutr 2011;6:241-260.

2 Delzenne NM, Neyrinck AM, Cani PD: Modulation of the gut microbiota by nutrients with prebiotic properties: consequences for host health in the context of obesity and metabolic syndrome. Microb Cell Fact 2011; 10(suppl 1):S10.

3 Sanz Y, Santacruz A, De Palma G: Insight into the role of gut microbiota in obesity. Interdiscp Perspect Infect Dis 2008: DOI:10.1155/2008/829101.

4 Angelaski E, Armougon F, Million M, Raoult D: The relationship between gut microbiota and weight gain in humans. Future Microbiol 2012;7:91-109.

5 Vrieze A, Holleman F, Zoetendal EG, de Vos WM, Hoekstra JB, Nieuwdorp M: The environment within: how gut microbiota may influence metabolism and body composition. Diabetologia 2010;53:606-613.

6 Harris K, Kassis A, Major G, Chou CJ: Is the gut microbiota a new factor contributing to obesity and its metabolic disorders? J Obes 2012;2012:879151.

7 Wexler HM: Bacteroides: the good, the bad, and the nitty-gritty. Clin Microbiol Rev 2007;20:593-621.

8 Ley RE, Turnbaugh PJ, Klein S, Gordon JI: Microbial ecology: human gut microbes associated with obesity. Nature 2006;444:1022-1023.

9 Turnbaugh PJ, Ley RE, Mahowald MA, Magrini V, Mardis ER, Gordon JI: An obesity-associated gut microbiome with increased capacity for energy harvest. Nature 2006;444:1027-1031.

10 Armougom F, Henry M, Vialettes B, Raccah D, Raoult D: Monitoring bacterial community of human gut microbiota reveals an increase in Lactobacillus in obese patients and methanogens in anorexic patients. PLoS One 2009; 4:e7125.

11 Duncan SH, Lobley GE, Holtrop G, Ince J, Johnstone AM, Louis P, Flint HJ: Human colonic microbiota associated with diet, obesity and weight loss. Int J Obes 2008;32:1720-1724.

12 Schwiertz A, Taras D, Schäfer K, Beijer S, Bos NA, Donus C, Hardt PD: Microbiota and SCFA in lean and overweight healthy subjects. Obesity (Silver Spring) 2010;18:190-195.

13 Blaut M, Klaut S: Intestinal microbiota and obesity. Handb Exp Pharmacol 2012;209:251.73.

14 Manco M, Putignani L, Bottazzo GF: Gut microbiota, lipopolysaccharides, and innate immunity in the pathogenesis of obesity and cardiovascular risk. Endocr Rev 2010;31:817-844.

15 Cani P, Amar J, Iglesias M, Poggi M, Knauf C, Bastelica D: Metabolic endotoxemia initiates obesity and insulin resistance. Diabetes 2007;56:1761-1772.

16 Matsuki T, Watanabe K, Fujimoto J, Takada T, Tanaka R: Use of 16S rRNA gene-targeted group-specific primers for real-time PCR analysis of predominant bacteria in human feces. Appl Environ Microbiol 2004;70:72207728.

17 Menard JP, Fenollar F, Henry M, Bretelle F, Raoult D: Molecular quantification of Gardnerella vaginalis and Atopobium vaginae loads to predict bacterial vaginosis. Clin Infect Dis 2008;47:33-43.

18 Penders J, Vink C, Driessen C, London N, Thijs C, Stobberinh EE: Quantification of Bifidobacterium spp., Escherichia coli and Clostridium difficile in faecal samples of breast-fed and formula-fed infants by real-time PCR. FEMS Microbiol Lett 2005;243:141-147.

19 Holmes E, Li JV, Athsnasiou T, Ashrafian H, Nicholson JK: Understanding the role of gut microbiome-host metabolic signal disruption in health and disease. Trends Microbiol 2011;19:349-359.

20 Zhang W, Cline MA, Gilbert ER: Hypothalamus-adipose tissue crosstalk: neuropeptide Y and the regulation of energy metabolism. Nutr Metab 2014;doi: 10.1186/1743-7075-11-27.

21 Caricilli AM, Saad MJA: The role of gut microbiota on insulin resistance. Nutrients 2013;5:829-851.

22 Santacruz A, Marcos A, Wärnberg J, Martí A, Matillas M, Campoy C: Interplay between weight loss and gut microbiota composition in overweight adolescents. Obesity (Silver Spring) 2009;17:1906-1915.

23 Koselak P, Sak-Golab A, Zahorska-Markiewick B, Aptekorz M, Zientara M, Martirosian G, Chudek J, OlszaneckaGlinianowicz M: Resting energy expenditure and gut microbiota in obese and normal weight subjects. Eur Rev Med Pharmacol Sci 2013;17:2816-2821. 
Radilla-Vázquez et al.: Gut Microbiota and Metabolic Endotoxemia in Young Obese Mexican Subjects

24 Woting A, Pfeiffer N, Loh G, Klaus S, Blaut M: Clostridium ramosum promotes high-fat diet-induced obesity in gnotobiotic mouse models. MBio 2014;5:e01530-14.

25 Millon M, Thuny F, Angelakis E, Casalta J-P, Giorgi R, Habib G, Raoult D: Lactobacillus reutery and Escherichia coli in the human gut microbiota may predict weight gain associated with vancomycin treatment. Nutr Diabetes 2013;3:e87.

26 Million M, Lagier JC, Yahav D, Paul M: Gut bacterial microbiota and obesity. Clin Microbiol Infect 2013;19: 305-313.

27 Ramachadran G: Gram-positive and Gram-negative bacterial toxins in sepsis. Virulence 2014;5:212-218.

28 Amar J, Burcelin R, Ruidavets JB, Cani PD, Fauvel J, Alessi MC, et al: Energy intake is associated with endotoxemia in apparently healthy men. Am J Clin Nutr 2008;87:1219-1223.

29 Hawkesworth S, Noore SE, Fulford AJC, Barclay GR, Darboe AA, Mark H, Nyan OA, Prentice AM: Evidence for metabolic endotoxemia in obese and diabetic Gambian women. Nutr Diabetes 2013;3:e83.

30 Aroutcheva A, Ling Z, Faro S: Prevotella bivia as a sourse of lipopolysaccharide in vagina. Anaerobe 2008;14: 256-260.

31 Fei N, Zhao L: An opportunistic pathogen isolated from the gut of an obese human causes obesity in germfree mice. ISME J 2013; 7:880-884. 